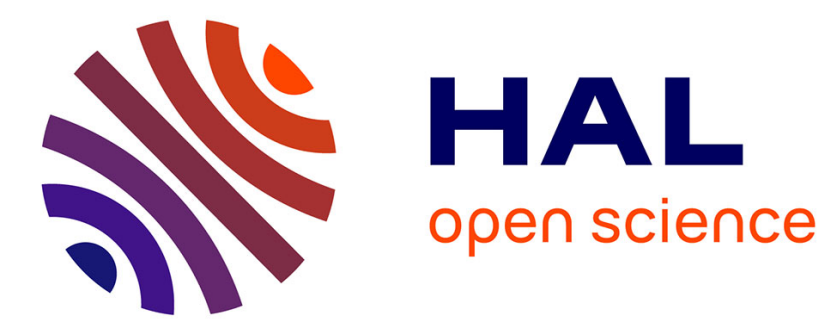

\title{
What history tells us XXXIX. CRISPR-Cas: From a prokaryotic immune system to a universal genome editing tool
}

Michel Morange

\section{- To cite this version:}

Michel Morange. What history tells us XXXIX. CRISPR-Cas: From a prokaryotic immune system to a universal genome editing tool . Journal of Biosciences, 2015. hal-01346782

\section{HAL Id: hal-01346782 \\ https://hal.science/hal-01346782}

Submitted on 27 Jul 2016

HAL is a multi-disciplinary open access archive for the deposit and dissemination of scientific research documents, whether they are published or not. The documents may come from teaching and research institutions in France or abroad, or from public or private research centers.
L'archive ouverte pluridisciplinaire HAL, est destinée au dépôt et à la diffusion de documents scientifiques de niveau recherche, publiés ou non, émanant des établissements d'enseignement et de recherche français ou étrangers, des laboratoires publics ou privés.

\section{(이)(\$)}

Distributed under a Creative Commons Attribution - NonCommercial - NoDerivatives| 4.0 


\section{What history tells us \\ XXXIX.}

CRISPR-Cas: From a prokaryotic immune system to a universal genome editing tool MICHEL MORANGE

Centre Cavaillès, République des Savoirs: lettres, sciences, philosophie USR 3608, Ecole normale supérieure, 29 rue d'Ulm, 75230 Paris Cedex 05, France

\section{(Fax, 33-144323941; Email, morange@biologie.ens.fr)}

Keywords: CRISPR-Cas system; genome editing; prokaryotic immune response; RNA interference

\section{Introduction}

In a previous contribution, I showed how the evidence for the existence of a CRISPR-based adaptive immunity in prokaryotes has been the result of a long and tortuous historical process (Morange 2015). After 2007, it was admitted that Clustered Regularly Interspaced Short Palindromic Repeat (CRISPR) loci harbour spacer sequences derived from phages and plasmids. These loci are transcribed, and the mRNA is matured into short crRNAs that guide the inactivation of phages and plasmids bearing sequences identical to those present in the spacers. The CRISPR loci are flanked by an ensemble of Cas genes involved in the immune response.

I will extend this story by describing how, in a few years, a universal genome editing tool emerged from the study of this system. This second part of the story was no less complex and tortuous than the first. It also involved numerous participants, only some of whom have been projected into the limelight. 
I will successively describe why, in 2009-2010, DNA was definitively considered as a possible target of the CRISPR-Cas response, and how the years 2011-2012 were crucial for a precise understanding of the mechanisms of CRISPR-Cas9 interference, but also for the conception of a new genome editing tool. In a third part, I will emphasize the importance of the previous essays on zinc-finger nucleases and Transcription Activator-Like Effector Nucleases (TALENs) in generating, at the beginning of 2013, the "CRISPR craze" (Pennisi 2013).

\section{DNA is the target!}

Transcription of the CRISPR repeated sequences and maturation of the RNA into short crRNAs guiding the inactivation of the invaders were rapidly demonstrated. The role of the Cas proteins in the process was also obvious, although the diversity of these proteins in the different organisms obscured the precise role of each of them. But how did these guide crRNAs interfere with the development of phages? Did they interact with the phage DNA, or with its RNA transcripts?

The initially preferred target was RNA. The first reason was the parallel between the immunity provided by the CRISPRCas system and the RNA interference response recently evidenced in eukaryotes. This parallel, publicized by Koonin (Makarova et al. 2006), was present in the minds of all experimenters. But there probably was a second reason to favour RNA over DNA. The possibility for a small RNA to interact with DNA had been often anticipated, but each time the hope had vanished: bacterial repressors were not RNAs, but proteins; antisense RNAs were efficient at the level of translation, not at the level of transcription. The choice of RNA as the target resulted also from the direct demonstration 
in an in vitro system of an "RNA-guided RNA cleavage by a CRISPR RNA-Cas protein complex" (Hale et al. 2009, 945). But three repeated observations directly supported the hypothesis that the target was, at least in certain systems, DNA: the fact that antisense sequences were as active as sense sequences in interference (Barrangou et al. 2007; Brouns et al. 2006); the observation that sequences of the invaders can be the target of the interference response even if they are not present in RNAs - a result shown very elegantly by the use of a self-splicing intron (Marraffani and Sontheimer 2008); and the evidence that fragments of phage genomes, corresponding to genes expressed late during infection, were as efficient in protecting as sequences expressed early during infection. Taking into account these hard facts, a series of reviews written in 2009-2010 supported the hypothesis that the target of the crRNAs could be DNA (Waters and Storz 2009; van der Oost et al. 2009; Marraffini and Sontheimer 2010). Even though Deveau et al. and Philippe Horvath and Rodolphe Barrangou preferred to remain cautious in their two reviews (2010), given the diversity of CRISPR-Cas systems in bacteria and archaea, at the end of the same year both supported the hypothesis that plasmid and bacteriophage double-stranded DNA were specifically cleaved during interference (Garneau et al. 2010; Bhaya et al. 2011), a result confirmed in vitro two years later (Gasiunas et al. 2012).

\section{The crucial years 2011-2012}

In March 2011, Emmanuelle Charpentier and her collaborators demonstrated in Streptococcus pyogenes the existence of a hitherto unobserved step in the maturation of the crRNAs: the participation of a trans-encoded small RNA, tracrRNA with a 24-nucleotide sequence complementary to the repeat regions 
of crRNA precursor transcripts (Deltcheva et al. 2011). The endogenous bacterial RNAse III was required for immunity, presumably because of its participation in the maturation of the crRNA - tracrRNA - Csn1 (Cas) complex.

A little more than one year later, a new publication by the same group demonstrated the DNAse activity of an in vitro system containing these two RNAS, the Csn1 protein rebaptized Cas 9, and a target DNA (Jinek et al. 2012). The precise point of DNA cleavage was determined and it was shown that two different domains of Cas 9 are involved in the cleavage of the two strands of DNA. It was demonstrated that the tracrRNA - crRNA - Cas9 complex is required for DNA targeting, and the precise interactions between this complex and the DNA target were determined. In addition, the paper described how the two RNAs could be positioned on one unique chimeric RNA guide molecule, making the system very easy to use. The demonstration that the system could be used to target any DNA sequence was provided by the construction of a chimeric RNA molecule guide able to target the GFP gene.

Despite the apparent continuity, there are two huge differences between the two papers. The first is centred around the process of RNA maturation, and the participation of Cas proteins in it. There are no discussions of what might be the target of the maturation complex, the mechanisms being "yet to be fully understood" (Deltcheva et al. 2011, 602). But the description that was provided drew a strong parallel between the eukaryotic interfering system acting on RNA and the CRISPR-Cas system, between the role of Dicer and of RNAse III, a point that did not escape the attention of commentators (Gottesman 2011). One year later, all the attention was focused on the activity of the Cas 9 nuclease, and its control by the two small RNAs that were now considered as partners in a 
"dual-RNA-guided DNA endonuclease" (Jinek et al. 2012, 816). The role of Csn1 (Cas9) had dramatically changed between the two studies.

There is a second major difference between the two articles. The system is now seen as a new potential tool for genome editing, superior to the pre-existing zinc fingers and TALE nucleases painfully constructed in previous years. In contrast to these systems, the same protein (nuclease) can be used in all experiments, the single (and easy) necessary change being in the sequence of the guide RNA. In addition, the specificity provided by the interaction between two oligonucleotide sequences was expected to outcompete that reached by an interaction between a protein and a nucleic acid.

What may have occurred between these two articles to explain this dramatic reinterpretation of the data, and reorientation of the work? The reader is not helped by the 2012 article, written within the new framework, and totally silent on what justified this reorientation. A review article published in Nature at the beginning of 2012 is often cited as a turning point (Wiendenheft et al. 2012). Its content does not justify such a privileged treatment. It is a bad habit on the part of scientists to cite the most recent reviews on a topic, without reading them!

So I can only hypothesize. One paper, briefly mentioned in the 2012 publication, appears to have been essential: published in August 2011 (Sapranauskas et al. 2011), it demonstrated, by the transfer of the CRISPr-Cas type II system of Streptococcus thermophilus into E. coli, that the Cas9 gene is the only Cas gene necessary in this system for interference, and initiated an analysis of the functions of the different domains of the protein encoded by this gene. This article is fundamental since it gave Csn1 (Cas 9) a radically new function in comparison with the 2011 article of Emmanuelle Charpentier's group, and 
strongly suggested that it directly exerted its nuclease activity on DNA.

The second important contribution was a review written by most of the experts in the field, consisting in classifying the different CRISPR-Cas systems (Makarova et al. 2011). In this review, the description of crRNA and tracrRNA was presented in parallel with observations on the essential role of Cas9 and the evidence for a DNA cleavage. Preparation of this review paper was probably facilitated the rapid circulation of information between those involved.

\section{From gene targeting to genome editing}

The "CRISPR craze" would not have been possible without the progressive transformation of another, fully independent field of research: the search for tools to inactivate targeted genes, to add new genes, and to replace genes by altered copies of them. These different objectives do not theoretically require the same tools. Cutting the DNA at a precise position is not required for the production of genetically modified organisms in which the foreign fragments of DNA are inserted at any position in the genome. In the production of knockout or knockin transgenic mice, in which an altered copy replaces the normal copy of a gene, cutting DNA is also not necessary: what is done is simply to select the rare embryonic stem cell clones where homologous recombination has occurred. But both strategies raise huge issues when applied to humans. For instance, the insertion of a transgene can occur close to an oncogene, and provoke a malignant disease in the recipient organism. The idea progressively emerged that the only safe strategy to orient the insertion of a transgene or to increase the efficiency of substitution was to cut DNA at the position where the insertion or the substitution had to occur, in order to 
increase the efficiency of the repair process by homologous and non-homologous recombination.

The first enzymes selected as candidates were restriction enzymes (homing meganucleases), which cut at very specific positions in the genome (Jacquier and Dujon 1985). This approach became fully efficient with the coupling of a nuclease with zinc-finger recognition motifs in which the rules of recognition of the targeted nucleotides are simple. Zincfinger coupled nucleases were the first demonstrated to be efficient for human therapeutic applications, through the inactivation of the gene encoding the HIV receptor (Perez et al. 2008; Carroll 2008). This success was hugely important in raising the visibility of this new experimental approach. It was immediately followed by the announcement of even better results obtained with TALENs (Christian et al. 2010; Miller et al. 2011). It led the authors of these studies to promote the replacement of the expression "gene targeting" by "genome editing" to emphasize the precision of these new tools (Urnov et al. 2010).

The rapid development of these tools at the end of the 2000s had prepared the ground for the CRISPR revolution. The term of editing was immediately adopted, and the superiority of the CRISPR-Cas9 system was easily demonstrated (Jinek et al. 2012).

\section{Conclusion}

A series of papers was published at the beginning of 2013 demonstrating the potential of the CRISPR-Cas9 editing system in bacteria, mouse and human cells, as well as in zebrafish. The most remarkable was the efficiency of the process, and the possibility of "multiplex" targeting (Cong et al. 2013; Mali et al. 2013; Hwang et al. 2013; Cho et al. 2013; 
Jiang et al. 2013). Homologous recombination can be favoured by inactivating one of the two active sites of Cas9, now nicking DNA instead of cutting it (Cong et al. 2013). In May of the same year, Rudolf Jaenisch's group demonstrated that the new tools not only efficiently inactivated target genes, but also induced the precise replacement of nucleotides in targeted genes (Wang et al. 2013). The way was open to germline modification. Various reviews transformed this complex history into a path to "rewriting a genome" (Charpentier and Doudna 2013; Doudna and Charpentier 2014).

What emerges from this brief historical sketch is that the CRISPR craze was the result of the rapid convergence of two projects and lines of research that had been fully distinct: the search for a mechanistic understanding of a new immune system discovered in prokaryotes and efforts to design efficient genome editing tools by the construction of specific endonucleases. The encounter was explosive because both fields had reached a similar degree of maturation and expectation at the same time.

An additional remark is that these extraordinary results were the fruit of a "traditional" way of doing biological research. Databases were important for the comparison of sequences and "deep sequencing" for the characterization of small RNAs, but the breakthrough came from the progressive analysis of the components, and the in vitro reconstitution of the systems, a strategy used since the early days of biochemistry! A result as important as the demonstration that interference occurred at the level of DNA was provided by the "old" Southern method (Garneau et al. 2010), not by new post-genomic ones!

But certainly the most significant result of this study is that many researchers participated in this adventure and 
contributed to one step or another, and several among them contributed both to the first steps and to the most recent developments. The 2011 review on the CRISPR-Cas systems, which was probably, as we suggested, an important trigger for the reorientation of the research, was signed by twelve authors. The Nobel Prize Committee is greatly to be pitied if it has to select only three names from the long list of contributors. The worst thing would be to choose not those who contributed the most, but those most gifted at rewriting history to their own advantage.

\section{Acknowledgements}

I am indebted to David Marsh for critical reading of the manuscript.

\section{References}

Barrangou R, Frenaux C, Deveau H, Richards M, Boyaval P, et al. 2007 CRISPR provides acquired resistance against viruses in prokaryotes. Science $\mathbf{3 1 5}$ 1709-1712 Bhaya D, Davison M and Barrangou R 2011 CRISP-Cas systems in bacteria and archaea: versatile small RNAs for adaptive defense and regulation. Annu. Rev. Genet. 45 273297

Brouns SJJ, Jore MM, Lundgren M, Westra ER, Slijkhuis RJH, et al. 2008 Small CRISPR RNAs guide antiviral defense in prokaryotes. Science 321 960-964

Carroll D 2008 Progress and prospects: zinc-finger nucleases as gene therapy agents. Gene Ther. 15 1463-1468 Charpentier E and Doudna JA 2013 Rewriting a genome. Nature 495 50-51 
Cho SW, Kim S, Kim JM and Kim J-S 2013 Targeted genome engineering in human cells with the Cas9 RNA-guided endonuclease. Nature Biotechnol. 31 230-232

Christian M, Cermak T, Doyle EL, Schmidt C, Zhang F, et al. 2010 Targeting DNA double-strand breaks with TAL effector nucleases. Genetics 186 757-761

Cong L, Rann FA, Cox D, Lin S, Barretto R, et al. 2013

Multiplex genome engineering using CRISPR/cas systems.

Science 339 819-823

Deltcheva E, Chylinski K, Sharma CM, Gonzales K, Chao Y, et al. 2011 CRISPR RNA maturation by trans-encoded small RNA and host factor RNase III. Nature 471 602-607

Deveau H, Garneau JE and Moineau S 2010 CRISPR/cas system and its role in phage-bacteria interactions. Annu. Rev. Microbiol. 64 475-493

Doudna JA and Charpentier E 2014 The new frontier of genome engineering with CRISPR-Cas9. Science 3461077 Garneau JE, Dupuis M-E, Villion M, Romero DA, Barrangou $\mathrm{R}$, et al. 2010 The CRISPR/Cas bacterial immune system cleaves bacteriophage and plasmid DNA. Nature 468 67-71 Gasiunas G, Barrangou R, Horvath P and Siksnys V 2012 Cas9-crRNA ribonucleoprotein complex mediates specific DNA cleavage for adaptive immunity in bacteria. Proc. Natl. Acad. Sci. USA 109 E2579-E2586

Gottesman S 2011 Dicing defence in bacteria. Nature 471 588-589

Hale CR, Zhao P, Olson S, Duff MO, Graveley BR, et al. 2009 RNA-guided RNA cleavage by a CRISPR RNA-Cas protein complex. Cell 139 945-956

Horvath P and Barrangou R 2010 CRISPR/Cas, the immune system of bacteria and archaea. Science 327 167-170 
Hwang WY, Fu Y, Reyon D, Maeder ML, Tsai SQ, et al. 2013 Efficient genome editing in zebrafish using a CRISPRCas system. Nature Biotechnol. 31 227-229 Jacquier A and Dujon B 1985 An intron-encoded protein is active in a gene conversion process that spreads an intron into a mitochondrial gene. Cell 41 383-394 Jiang W, Bikard D, Cox D, Zhang F and Marraffini LA 2013 RNA-guided editing of bacterial genomes using CRISPR-Cas systems. Nature Biotechnol. 31 233-239

Jinek M, Chylinski K, Fonfara I, Hauer M, Doudna JA and Charpentier E 2012 A programmable Dual-RNA-guided DNA endonuclease in adaptive bacterial immunity. Science $\mathbf{3 3 7}$ 816-821

Makarova KS, Grishin NV, Shabalina SA, Wolf YI and Koonin EV 2006 A putative RNA-interference-based immune system in prokaryotes: computational analysis of the predicted enzymatic machinery, functional analogies with eukaryotic RNAi, and hypothetical mechanisms of action. Biol. Direct 1 7

Makarova KS, Haft DH, Barrangou R, Brouns SJJ, Charpentier E, et al. 2011 Evolution and classification of the CRISPR-Cas systems. Nature Rev. Microbiol. 9 467-477 Mali P, Yang L, Esvelt KM, Aach J, Guelt M, et al. 2013 RNA-guided human genome engineering via Cas9. Science 339 823-826

Marraffini LA and Sontheimer EJ 2008 CRISPR interference limits horizontal gene transfer in Staphylococci by targeting DNA. Science 322 1843-1845

Marraffini LA and Sontheimer EJ 2010 CRISPR interference: RNA-directed adaptive immunity in bacteria and archaea. Nature Rev. Genet. 11 181-190 
Miller JC, Tan S, Qiao G, Barlow KA, Wang J, et al. 2011 A TALE nuclease architecture for efficient genome editing.

Nature Biotechnol. 29 143-148

Morange M 2015 CRISPR-Cas: the discovery of an immune system in prokaryotes. J. Biosci. 40 1-3

Pennisi E 2013 The CRISPR craze. Science 341 833-836 Perez EE, Wang J, Miller JC, Jouvenot Y, Kim KA, et al. 2008 Establishment of HIV-1 resistance in $\mathrm{CD}^{+}{ }^{+} \mathrm{T}$ cells by genome editing using zinc-finger nucleases. Nature Biotechnol. 26 808-816

Sapranauskas R, Gasiunas G, Fremaux C, Barrangou R, Horvath P and Siksnys V 2011 The Streptococcus thermophilus CRISPR/Cas system provides immunity in Escherichia coli. Nucleic Acids Res. 39 9275-9282 Urnov FD, Rebar E J, Holmes MC, Zhang HS and Gregory PD 2010 Genome editing with engineered zinc finger nucleases. Nature Rev. Genet. 11 636-646 Van der Oost J, Jore MM, Westra ER, Lundgren M and Brouns SJJ 2009 CRISPR-based adaptive and heritable immunity in prokaryotes. Trends Biochem. Sci. 34 401-407 Wang H, Yang H, Shivalila CS, Dawlaty MM, Cheng AW, et al. 2013 One-step generation of mice carrying mutations in multiple genes by CRISPR/Cas-mediated genome engineering. Cell 153 910-918 Waters LS and Storz G 2009 Regulatory RNAs in bacteria. Cell 136 615-628

Wiedenheft B, Sternberg SH and Doudna JA RNA-guided genetic silencing systems in bacteria and archaea. Nature $\mathbf{4 8 2}$ 331-338 